\title{
UK-69,753, A NOVEL MEMBER OF THE EFROTOMYCIN FAMILY OF ANTIBIOTICS \\ II. STRUCTURE DETERMINATION AND BIOLOGICAL ACTIVITY
}

\author{
Martin R. Jefson, Jon Bordner, Catherine P. Reese \\ and EARL B. WhIPPLE \\ Pfizer Central Research, \\ Groton, Connecticut, U.S.A.
}

(Received for publication June 9, 1989)

\begin{abstract}
A novel antibiotic, UK-69,753, has been isolated from a submerged fermentation of Amycolatopsis orientalis strain N731-15. UK-69,753 has been assigned the structure 1 using spectroscopic means, primarily by NMR analysis. UK-69,753 is a glycoside of factumycin (A40A), a previously reported member of a small group of antibiotics related to aurodox and efrotomycin. UK-69,753 was shown to have potent activity both in vitro and in vivo against the swine pathogen Treponema hyodysenteriae.
\end{abstract}

In the preceding paper ${ }^{11}$, we have described the taxonomy, fermentation and isolation of UK-69,753 (1), a novel member of the efrotomycin ${ }^{2)}$ family of antibiotics. In this paper we describe the structure elucidation of UK-69,753 along with its antibacterial activity.

\section{Results and Discussion}

\section{Structure Determination of UK-69,753}

The structure of UK-69,753 (1) has been determined by spectroscopic means, relying heavily on the results of NMR analysis. ${ }^{1} \mathrm{H},{ }^{13} \mathrm{C}$, carbon multiplicity (distortionless enhancement by polarization transfer: $\mathrm{DEPT}^{3)}$ and 2D (homonuclear correlation: $\mathrm{COSY}^{4)}$ and heteronuclear correlation: HETCOR ${ }^{5)}$ ) NMR spectra were recorded on $\mathrm{UK}-69,753$ in $\mathrm{CD}_{3} \mathrm{OD}$, and the results of these experiments are summarized in Table 1. The ${ }^{13} \mathrm{C}$ NMR spectrum showed 57 distinct resonances with one line at $130.41 \mathrm{ppm}$ accounting for two carbons, indicating that UK-69,753 contains 58 carbon atoms. Using the data available primarily from the two correlation experiments, eight distinct spin systems comprising 47 carbons were identified which correspond to the molecular fragments 2 through $\mathbf{9}$. The olefinic proton resonances of fragments 2, 7, and 8 were unambiguously assigned and measurement of the vicinal coupling constants of these resonances in the ${ }^{1} \mathrm{H}$ NMR spectrum at $500 \mathrm{MHz}$ (Fig. 1) allowed for assignment of the configuration of each disubstituted olefin in these fragments. The configuration of the two trisubstituted olefins (fragments 7 and 8 ) were both assigned as drawn on the basis of nuclear Overhauser effect (NOE) experiments ${ }^{\dagger}$. The carbonyl and quaternary olefinic carbons in fragments 7 and 8 were assigned via multiple bond heteronuclear correlation (MBHC) to nearby carbons bearing protons.

Consideration of the part structures $2 \sim 9$ assembled from an analysis of NMR data lead to the hypothesis that UK-69,753 is a novel member of a small group of antibiotics characterized by compounds

\footnotetext{
$\uparrow$ The nuclear Overhauser polarizations, observed at $500 \mathrm{MHz}$, were consistently negative.
} 
Table 1. A summary of the ${ }^{1} \mathrm{H},{ }^{13} \mathrm{C}, \mathrm{DEPT}$, homonuclear (COSY) and heteronuclear (HETCOR) correlation data for UK-69,753 (1) $\left(\mathrm{CD}_{3} \mathrm{OD}\right)$.

\begin{tabular}{|c|c|c|c|c|}
\hline Index & ${ }^{13} \mathrm{C} \operatorname{shift}{ }^{a}(M)^{b}$ & ${ }^{1} \mathrm{H}$ shifft ${ }^{\mathrm{a}, \mathrm{c}}(J)$ & ${ }^{1} \mathrm{H}-{ }^{1} \mathrm{H}$ connections ${ }^{\mathrm{d}}$ & Assignment ${ }^{\mathrm{e}}$ \\
\hline 1 & $198.52(0)$ & & & 7 \\
\hline 2 & $176.99(0)$ & & & 26 \\
\hline 3 & $167.32(0)$ & & & 5 \\
\hline 4 & $163.72(0)$ & & & 1 \\
\hline 5 & $142.81(1)$ & $7.60 \mathrm{~d}(J=7.6)$ & 23 & 3 \\
\hline 6 & $142.17(1)$ & $6.91 \mathrm{dd}(J=1.4,11.1)$ & 17,55 & 9 \\
\hline 7 & $142.04(1)$ & $6.64 \mathrm{dd}(J=10.8,14.5)$ & 11,17 & 11 \\
\hline 8 & $137.88(0)$ & & & 8 \\
\hline 9 & $137.14(0)$ & & & 20 \\
\hline 10 & $136.44(1)$ & $5.60 \mathrm{dd}(J=6.0,15.3)$ & 19,31 & 33 \\
\hline 11 & $134.99(1)$ & $6.46 \mathrm{dd}(J=10.8,14.6)$ & 7,12 & 12 \\
\hline 12 & $133.81(1)$ & $6.83 \mathrm{dd}(J=11.7,14.6)$ & 11,13 & 13 \\
\hline 13 & $132.30(1)$ & $6.28 \mathrm{dd}(J=11.1,11.7)$ & 12,15 & 14 \\
\hline $14 a^{\dagger}$ & $130.41(1)$ & $5.65 \mathrm{~m}$ & 18,43 & 23 \\
\hline $14 b^{\dagger}$ & $130.41(1)$ & $5.96 \mathrm{dd}(J=1.2,11.0)$ & 18,56 & 21 \\
\hline 15 & $130.24(1)$ & $5.62 \mathrm{~m}$ & 13,38 & 15 \\
\hline 16 & $130.21(1)$ & $6.00 \mathrm{dd}(J=10.7,11.1)$ & $19,20,52$ & 35 \\
\hline 17 & $129.98(1)$ & $6.72 \mathrm{dd}(J=11.1,14.5)$ & 6,7 & 10 \\
\hline 18 & 128.44 (1) & $6.50 \mathrm{dd}(J=11.0,15.5)$ & $14 \mathrm{a}, 14 \mathrm{~b}, 43$ & 22 \\
\hline 19 & $128.18(1)$ & $6.53 \mathrm{dd}(J=11.1,15.3)$ & $10,16,31$ & 34 \\
\hline 20 & $126.67(1)$ & $5.48 \mathrm{dq}(J=7.3,10.7)$ & 16,52 & 36 \\
\hline 21 & $112.26(0)$ & & & 6 \\
\hline 22 & $104.14(1)$ & $4.62 \mathrm{~d}(J=7.2)$ & 32 & $1^{\prime}$ \\
\hline 23 & $101.47(1)$ & $6.10 \mathrm{~d}(J=7.6)$ & 5 & 4 \\
\hline 24 & $100.33(1)$ & $4.91 \mathrm{br} \mathrm{s}$ & 26 & $1^{\prime \prime}$ \\
\hline 25 & $99.56(0)$ & & & 28 \\
\hline 26 & $89.98(1)$ & 3.46 & 24,35 & $2^{\prime \prime *}$ \\
\hline 27 & $83.41(1)$ & 3.67 & 45 & 30 \\
\hline 28 & $83.22(1)$ & 3.68 & 29,33 & $3^{\prime}$ \\
\hline 29 & $82.59(1)$ & 3.31 & 28,37 & $4^{\prime}$ \\
\hline 30 & $82.21(1)$ & 3.44 & 47 & $19 *$ \\
\hline 31 & $77.76(1)$ & $4.18 \mathrm{~d}(J=6.0)$ & 10,19 & 32 \\
\hline 32 & $74.05(1)$ & 3.33 & 35,36 & $4^{\prime \prime}$ \\
\hline 33 & $73.47(1)$ & 3.36 & 22,28 & $2^{\prime}$ \\
\hline 34 & $73.45(1)$ & 3.86 & 38 & 17 \\
\hline 35 & $71.98(1)$ & 3.66 & 26,32 & $3^{\prime \prime}$ \\
\hline 36 & $70.85(1)$ & 3.77 & 32,51 & $5^{\prime \prime}$ \\
\hline 37 & $69.74(1)$ & 3.84 & 29,50 & $5^{\prime}$ \\
\hline 38 & $69.09(1)$ & $4.43 \mathrm{t}(J=8.5)$ & 15,34 & 16 \\
\hline 39 & $62.21(3)$ & $3.61 \mathrm{~s}$ & & $3^{\prime}-\mathrm{OCH}_{3}$ \\
\hline 40 & $59.36(3)$ & $3.43 \mathrm{~s}$ & & $2 "-\mathrm{OCH}_{3}$ \\
\hline 41 & $58.21(1)$ & $2.35 \mathrm{dd}(J=3.5,9.9)$ & 49 & 27 \\
\hline 42 & $56.39(3)$ & $3.12 \mathrm{~s}$ & & $19-\mathrm{OCH}_{3}$ \\
\hline 43 & $42.20(2)$ & 3.90 & $14 \mathrm{a}, 18, \mathrm{NH}$ & 24 \\
\hline 44 & $40.30(0)$ & & & 31 \\
\hline 45 & $38.18(2)$ & $\begin{array}{l}1.51 \mathrm{t}(J=11.7) \\
2.21 \mathrm{dd}(J=4.0,11.7)\end{array}$ & 27 & 29 \\
\hline 46 & $37.44(3)$ & $3.46 \mathrm{~s}$ & & 38 \\
\hline 47 & $37.01(1)$ & $2.10 \mathrm{~m}$ & $30,34,57$ & 18 \\
\hline 48 & $23.13(3)$ & $1.01 \mathrm{~s}$ & & 44 \\
\hline 49 & $21.65(2)$ & $1.70 \mathrm{~m}$ & 41,54 & 42 \\
\hline 50 & $18.27(3)$ & $1.22 \mathrm{~d}(J=6.7)$ & 37 & $6^{\prime}$ \\
\hline 51 & $18.15(3)$ & $1.28 \mathrm{~d}(J=6.0)$ & 36 & $6^{\prime \prime}$ \\
\hline 52 & $13.71(3)$ & 1.74 br $\mathrm{d}(J=7.3)$ & 16,20 & 37 \\
\hline 53 & $13.35(3)$ & $0.82 \mathrm{~s}$ & & 45 \\
\hline
\end{tabular}


Table 1. (Continued)

\begin{tabular}{ccccc}
\hline Index & ${ }^{13} \mathrm{C}$ shift $^{\mathrm{a}}(\mathrm{M})^{\mathrm{b}}$ & ${ }^{1} \mathrm{H}$ shift ${ }^{\mathrm{a}, \mathrm{c}}(J)$ & ${ }^{1} \mathrm{H}^{1}{ }^{\mathrm{H}}$ connections $^{\mathrm{d}}$ & Assignment $^{\mathrm{e}}$ \\
\hline 54 & $12.47(3)$ & $0.92 \mathrm{t}(J=7.0)$ & 49 & 43 \\
55 & $11.73(3)$ & $1.98 \mathrm{~d}(J=1.4)$ & 6 & 39 \\
56 & $11.18(3)$ & $1.64 \mathrm{~d}(J=1.2)$ & $14 \mathrm{~b}$ & 41 \\
57 & $9.70(3)$ & $0.72 \mathrm{~d}(J=5.9)$ & 47 & 40 \\
\hline
\end{tabular}

a Chemical shifts reported in ppm.

b $\mathrm{M}$; the number of protons attached to the carbon line.

c The chemical shift of the protons attached to the carbon.

d ${ }^{1} \mathrm{H}-{ }^{1} \mathrm{H}$ connections are listed by index.

e Assignments refer to the number system in structure 1 .

* These assignments are interchangeable.

$\dagger$ These carbon lines are coincidentally degenerate.

$J$ : Coupling constant in $\mathrm{Hz}$.

Fig. 1. ${ }^{1} \mathrm{H}$ NMR spectrum of $\mathrm{UK}-69,753$ (1) $\left(500 \mathrm{MHz}, \mathrm{CD}_{3} \mathrm{OD}\right)$.

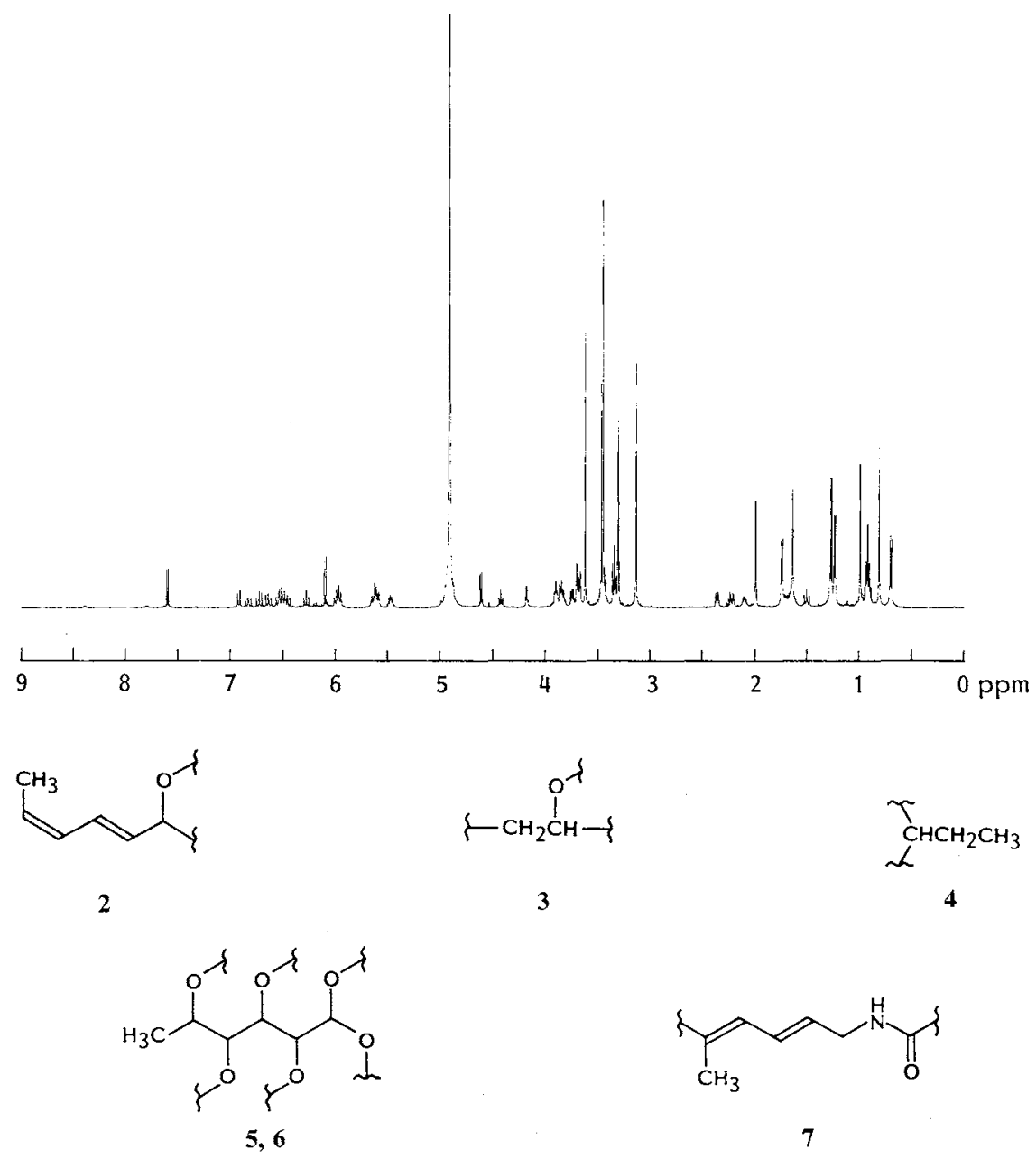

such as aurodox ${ }^{6)}$, efrotomycin ${ }^{2)}$ and factumycin ${ }^{7)}$. The UV spectrum (Table 3) of UK-69,753 in methanol shows absorbance maxima at 232 and $358 \mathrm{~nm}$, and is consistent with this hypothesis. The longer wavelength absorbance is characteristic of the tetraenone-4-hydroxy-2-pyridone chromophore which is part of the 
<smiles>[Y]OC([3H])C(C)C(O[3H])C(/C=C\C=C\C=C\C=C(/C)C([3H])=O)OC</smiles>

8 $\nvdash \mathrm{CH}=\mathrm{CH} \longrightarrow$

9

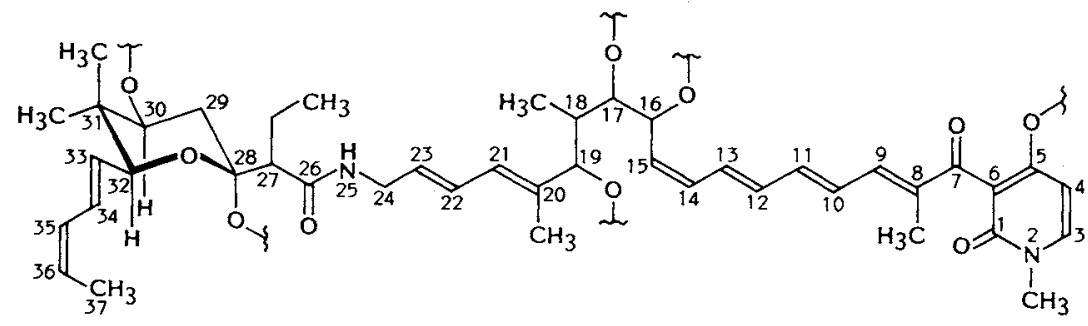

10<smiles>C/C=C\C=C/[C@H]1OC(O)(C(CC)C(=O)NC/C=C/C=C(\C)C(OC)C(C)C=O)CC2(O)OC1C2(C)C</smiles>

11

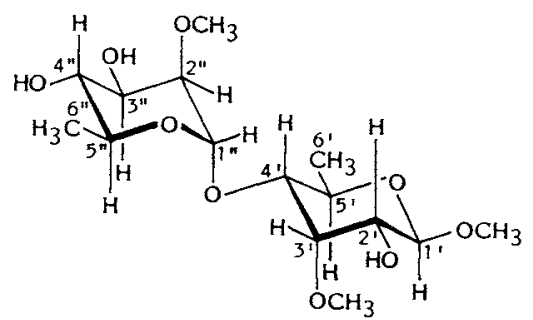

12

structure of only two members of this class, factumycin (A40A) and its stereoisomer $\mathrm{A} 73 \mathrm{~A}^{8}$. The presence of sugar residues in the structure of UK-69,753, as evidenced by 5 and $\mathbf{6}$, distinguishes it from the two aglycones A40A and A73A.

Using the structure of factumycin as a model, the part structures $2 \sim 4$ and $7 \sim 9$ can be combined to give 10, the backbone of the aglycone portion of the structure of UK-69,753. All of the structural elements of 10 not defined in the analysis above can be assigned from the COSY, HETCOR and MBHC spectra, including the N-2 methyl (37.44; $3.46 \mathrm{ppm})$, carbons C-1 (163.72), C-5 (167.32) and C-6 (112.26) of the pyridone ring, the hemiacetal C-28 (99.56) and the quaternary carbon C-31 (40.30) bearing geminal methyls (23.13; 1.01 and $13.35 ; 0.82)$. A comparison of the coupling constants observed for $32-\mathrm{H}(J=6.0 \mathrm{~Hz}), 30-\mathrm{H}$ $(J=4.0$ and $11.7 \mathrm{~Hz}), 29-\mathrm{H}_{\mathrm{eq}}(J=4.0$ and $11.7 \mathrm{~Hz})$ and $29-\mathrm{H}_{\mathrm{ax}}(J=11.7$ and $11.7 \mathrm{~Hz})$ in 10 with those of the corresponding protons in 11 , a degradation product isolated from the sodium metaperiodate oxidation of kirrothricin ${ }^{9)}$, allows for the assignment of the relative stereochemistry of the cyclic hemiacetal moiety (C-28 through C-32) as drawn in 10. Attempts to confirm these stereochemical assignments by direct observation of NOE's were inconclusive.

The structure of the carbohydrate portion of UK-69,753 was determined by degradation and X-ray crystallography. UK-69,753 was treated with anhydrous $\mathrm{HCl}$ in methanol at room temperature for 5 hours, resulting in the formation of $\mathbf{1 2}$, the $O$-methylglycoside of a disaccharide with a molecular formula of $\mathrm{C}_{15} \mathrm{H}_{28} \mathrm{O}_{9}$. Careful recrystallization of $\mathbf{1 2}$ from 2-propanol gave crystals suitable for single crystal X-ray analysis which provided the structure for $\mathbf{1 2}$ shown below. A perspective diagram of $\mathbf{1 2}$ is shown in Fig. 
2, and a summary of the NMR data for $\mathbf{1 2}$ is found in Table 2.

In order to complete the structure of UK69,753 , the location of the disaccharide and the remaining methoxyl group on the aglycone $\mathbf{1 0}$ needed to be determined. An isotope shift experiment in $\mathrm{CDCl}_{3}$ indicated that the substituents on carbons C-5, C-16, C-17, and C-28 are hydroxyl groups, so that the disaccharide and methoxyl substituents are attached at either $\mathrm{C}-19$ or $\mathrm{C}-30$. The substituent at $\mathrm{C}-19$ was assigned as a methoxyl group via multiple bond HETCOR, thus requiring that the disaccharide substituent be attached at C-30 and leading to the final assignment of the structure of UK-69,753 as 1. The molecular formula of UK-69,753 is thus determined to be $\mathrm{C}_{58} \mathrm{H}_{86} \mathrm{~N}_{2} \mathrm{O}_{18}$ with a MW of 1,098 . This formula was directly
Fig. 2. Single crystal X-ray structure of $\mathbf{1 2}$.

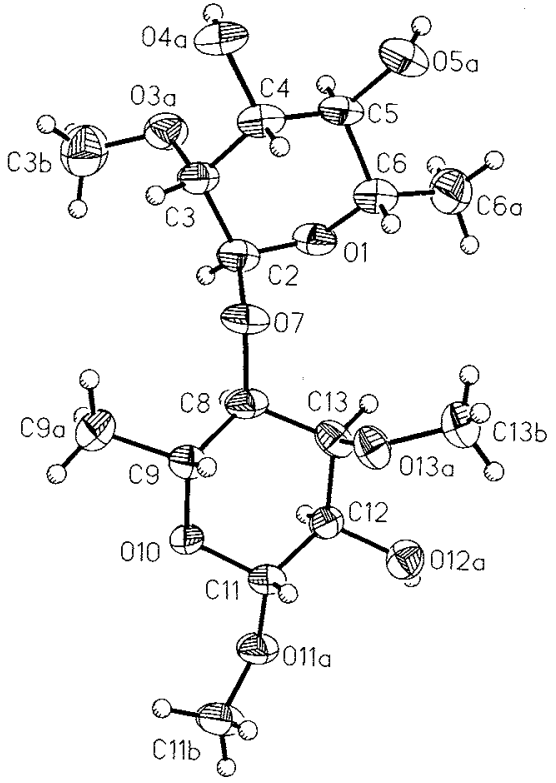

Table 2. A summary of the ${ }^{1} \mathrm{H},{ }^{13} \mathrm{C}$, DEPT, homonuclear (COSY) and heteronuclear (HETCOR) correlation data for compound $12\left(\mathrm{CDCl}_{3}\right)$.

\begin{tabular}{cclcc}
\hline Index & ${ }^{13} \mathrm{C} \mathrm{shift}^{\mathrm{a}}(\mathrm{M})^{\mathrm{b}}$ & ${ }^{1} \mathrm{H} \mathrm{shift}^{\mathrm{a}, \mathrm{c}}(J)$ & ${ }^{1} \mathrm{H}^{1}{ }^{1} \mathrm{H}$ connections ${ }^{\mathrm{d}}$ & Assignment \\
\hline 1 & $101.87(1)$ & $4.45 \mathrm{~d}(J=7.5)$ & 7 & $1^{\prime}$ \\
2 & $98.23(1)$ & $4.92 \mathrm{br} \mathrm{s}$ & 4 & $1^{\prime \prime}$ \\
3 & $80.88(1)$ & 3.40 & 10,5 & $4^{\prime}$ \\
4 & $80.23(1)$ & 3.48 & 2,8 & $2^{\prime \prime}$ \\
5 & $80.18(1)$ & 3.76 & 3,7 & $3^{\prime}$ \\
6 & $73.70(1)$ & 3.38 & 8,9 & $4^{\prime \prime}$ \\
7 & $72.08(1)$ & 3.46 & 1,5 & $3^{\prime \prime}$ \\
8 & $71.38(1)$ & 3.70 & 4,6 & $5^{\prime \prime}$ \\
9 & $68.94(1)$ & 3.77 & 6,15 & $5^{\prime}$ \\
10 & $68.82(1)$ & $3.85 \mathrm{dq}(J=6.5,9.7)$ & 3,14 & $\mathrm{OCH}_{3}$ \\
11 & $61.42(3)$ & $3.61 \mathrm{~s}$ & & $\mathrm{OCH}_{3}$ \\
12 & $58.89(3)$ & $3.45 \mathrm{~s}$ & & $\mathrm{OCH}_{3}$ \\
13 & $57.00(3)$ & $3.51 \mathrm{~s}$ & 10 & $6^{\prime}$ \\
14 & $17.78(3)$ & $1.27 \mathrm{~d}(J=6.5)$ & 9 & $6^{\prime \prime}$ \\
15 & $17.60(3)$ & $1.32 \mathrm{~d}(J=6.5)$ & & \\
\hline
\end{tabular}

a Chemical shifts reported in ppm.

b $\mathrm{M}$; the number of protons attached to the carbon line.

c The chemical shift of the protons attached to the carbon.

d ${ }^{1} \mathrm{H}-{ }^{1} \mathrm{H}$ connections are listed by index.

$J$ : Coupling constant in $\mathrm{Hz}$.

Table 3. Selected physico-chemical properties of UK-69,753.

UV $\lambda_{\max }^{\mathrm{MeOH}} \mathrm{nm}(\varepsilon)$

Combustion analysis

Negative ion FAB-MS

Optical rotation $[\alpha]_{\mathrm{D}}^{25}$

IR $(\mathrm{KBr}) \mathrm{cm}^{-1}$
$232(58,240), 358(36,320)$

Calcd for $\mathrm{C}_{58} \mathrm{H}_{86} \mathrm{~N}_{2} \mathrm{O}_{18}$ : C 63.37, H 7.82, N 2.55

Found:

C $63.34, \mathrm{H} 7.95$, N 2.19

$1,097(\mathrm{M}-\mathrm{H})^{-}$

$-134.1^{\circ}(c 0.44, \mathrm{MeOH})$

$3416,2967,2926,1648,1585,1453,1414,1380,1259,1193,1083,1025$ 


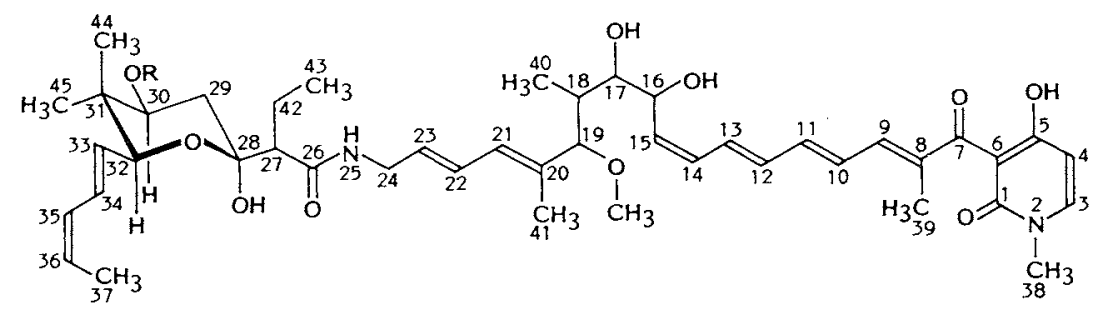

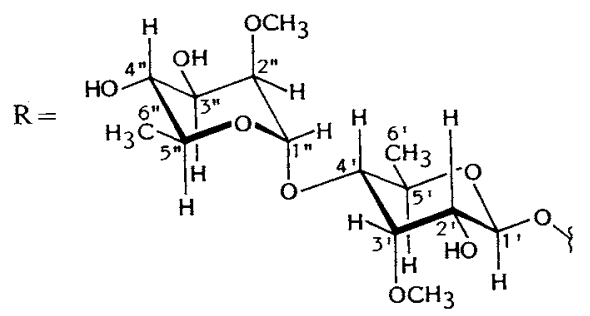

UK-69,753 (1)

Table 4. In vitro antibacterial activity of UK-69,753.

\begin{tabular}{lc}
\hline \multicolumn{1}{c}{ Organism } & $\begin{array}{c}\text { MIC } \\
(\mu \mathrm{g} / \mathrm{ml})\end{array}$ \\
\hline Staphylococcus aureus 01A106 & $>100$ \\
Escherichia coli 51 A266 & $>100$ \\
Pasteurella multocida 59A006 & 6.25 \\
P. haemolytica 59B018 & 6.25 \\
Bordetella bronchiseptica 73A006 & 100 \\
Clostridium perfringens $10 \mathrm{~A} 006$ & 6.25 \\
C. difficile 10J002 & 0.39 \\
Actinomyces pyogenes $14 \mathrm{D} 008$ & 25 \\
Actinobacillus pleuropneumoniae 54B004 & 12.5 \\
Bacteroides fragilis 78C024 & 100 \\
Treponema hyodysenteriae 94A008 & 0.78 \\
\hline
\end{tabular}

combustion analysis (Table 3 ).

The spectroscopic analysis described above has served to characterize the structure of UK-69,753 as 1, a novel glycosylated antibiotic related to efrotomycin. Previously reported glycosides in this antibiotic class include efrotomycin and the related phenelfamycin ${ }^{10)}$ and LL-E19020 ${ }^{11)}$ complexes. The structure of UK-69,753 represents an interesting hybrid of structural elements found in other members of this class. The aglycone of UK-69,753 is identical in structure to factumycin (A40A) (or a stereoisomer), while the disaccharide moiety of UK-69,753 is nearly identical to the disaccharide of efrotomycin, differing only in that the C-4" substituent is a hydroxyl in UK-69,753 as compared to a methoxyl group at C-4" in efrotomycin.

\section{Biological Activity of UK-69,753}

The in vitro antibacterial activity of UK-69,753 against a battery of veterinary pathogens was measured and the data from this study are summarized in Table 4 . The spectrum of antibacterial activity observed for UK-69,753 is similar to that reported for other members of this structure class ${ }^{12,13)}$. UK-69,753 exhibited particularly good potency against certain anaerobic bacteria such as Clostridium difficile and Treponema hyodysenteriae, a causative agent of swine dysentery. In a in vivo study, UK-69,753 was effective 
when orally administered to mice colonized with $T$. hyodysenteriae (Table 5 ). No viable $T$. hyodysenteriae cells were detectable from fecal pellets of mice treated with 7.1 or $3.6 \mathrm{mg} / \mathrm{kg} /$ day of UK-69,753, even at 12 days post-treatment. Treatment with $1.8 \mathrm{mg} / \mathrm{kg} / \mathrm{day}$ also affected colonization, although at this level only $60 \%$ of the treated mice remained free of infection by day-5 post-treatment.

\section{Experimental}

\section{General Procedures}

Samples of UK-69,753 used in the spectroscopic and biological studies described herein were isolated as reported in the companion paper to this report ${ }^{1)}$, and further purified by preparative HPLC using a Rainin Dynamax C18 column (21.4 mm i.d. $\times 25 \mathrm{~cm}, 8 \mu \mathrm{m}$ irregular particle, 60 Angstrom pore) eluted with $35 \%$ acetonitrile $-65 \% 0.05 \mathrm{M} \mathrm{KH}_{2} \mathrm{PO}_{4}(\mathrm{pH} 3.25)$ at a flow rate of $10 \mathrm{ml} /$ minute. Fractions containing pure UK-69,753 were combined and the acetonitrile was removed under reduced pressure. The UK-69,753 was then extracted into ethyl acetate, washed with distilled water, dried over $\mathrm{Na}_{2} \mathrm{SO}_{4}$, filtered and evaporated to give a bright yellow solid.

The NMR studies leading to the structure assignment were conducted on a Brucker WM-250 spectrometer, modified to incorporate a pulse programmer and Aspect-3000 data system. All of the experiments described used standard automation programs supplied by the manufacturer. The final assignments were verified, (COSY), and extended by inclusion of long-range heteronuclear shift correlations and NOE difference spectra, on a Brucker AM-500 spectrometer. The long-range heteronuclear shift correlation experiment utilized the same standard pulse sequence employed for the one-bond correlations, with delays scaled to ${ }^{13} \mathrm{C},{ }^{1} \mathrm{H}$ couplings of approximately $5 \mathrm{~Hz}$.

Isotope shift measurements in $\mathrm{CDCl}_{3}$ solution consisted of identically measuring the ${ }^{13} \mathrm{C}$ spectrum following successive washes with $\mathrm{H}_{2} \mathrm{O}-\mathrm{D}_{2} \mathrm{O}(1: 1), \mathrm{H}_{2} \mathrm{O}$, and finally, $\mathrm{D}_{2} \mathrm{O}$. In the latter two instances, the washes were repeated several times prior to recording the ${ }^{13} \mathrm{C}$ spectrum.

FAB-MS were recorded on a VG Analytical 70/250-S mass spectrometer in the negative ion mode using a dithiothreitol - dithioerythritol matrix. UV spectra were measured on a Hewlett-Packard HP 8450A diode array spectrophotometer. IR spectra were recorded on a Perkin-Elmer PE 1420 ratio recording IR spectrophotometer. Optical rotations were measured using a Perkin-Elmer PE 241 MC polarimeter.

\section{Preparation of 12}

To a solution of $2.0 \mathrm{~g}$ of UK-69,753 in $80 \mathrm{ml}$ of methanol was added $40 \mathrm{ml}$ of anhydrous $\mathrm{HCl}$ in methanol which was prepared by the addition of $2.0 \mathrm{ml}$ of acetyl chloride to $40 \mathrm{ml}$ of anhydrous methanol. The resulting red-brown mixture was stirred at room temperature for 5 hours, at which time it was concentrated to a brown residue under reduced pressure. The residue was loaded onto a silica gel column which was eluted with chloroform - methanol $(19: 1)$ to give $135 \mathrm{mg}$ of 12 as an off-white solid. This material was further purified by recrystallization from 2-propanol to yield $57 \mathrm{mg}$ of colorless needles with $\mathrm{mp}$ $155 \sim 157^{\circ} \mathrm{C},[\alpha]_{\mathrm{D}}^{25}-37.8^{\circ}\left(\mathrm{c} 1.07, \mathrm{CHCl}_{3}\right)$. The NMR analysis of $\mathbf{1 2}$ is summarized in Table 2 and its single-crystal $\mathrm{X}$-ray structure is shown in Fig. 2.

\section{Single Crystai X-Ray Analysis of $\mathbf{1 2}$}

A representative crystal was surveyed and a 1 Angstrom data set (maximum $\sin \theta / \lambda=0.5$ ) was collected on a Nicolet $\mathrm{R} 3 \mathrm{~m} / \mu$ diffractometer. Atomic scattering factors were taken from the International Tables for X-ray Crystallography ${ }^{14)}$. All crystallographic calculations were facilitated by the SHELXTL ${ }^{15)}$ system. All diffractometer data were collected at room temperature.

A trial structure was obtained by direct methods. This trial structure refined routinely. Hydrogen positions were calculated wherever possible. The methyl hydrogen parameters were added to the structure factor calculations but were not refined. The shifts calculated in the final cycle of least squares refinement were all less than $0: 1$ of their corresponding standard deviations. The final R-index was 0.034 . A final difference Fourier revealed no missing or misplaced electron density.

The refined structure was plotted using the SHELXTL plotting package (Fig. 2). Coordinates, 
anisotropic temperature factors, distances and angles are available as supplementary material.

Antimicrobial Susceptibility Test

MICs were determined as described by Dirlam et al. ${ }^{16)}$ except that all anaerobes were tested on Tryptose agar (Difco) supplemented with $5 \%$ bovine blood (TBA) and incubated 48 hours at $39^{\circ} \mathrm{C}$ in a Coy (Ann Arbor, Mich.) anaerobe chamber containing an $\mathrm{N}_{2}-\mathrm{CO}_{2}-\mathrm{H}_{2}(80: 10: 10)$ atmosphere. MICs for aerobes were determined in an identical manner except Brain heart infusion (BHI) agar (Difco) was used and plates were incubated acrobically at $37^{\circ} \mathrm{C}$ for $18 \sim 20$ hours.

\section{Mouse Treponema hyodysenteriae Colonization Model}

Female CF-1 mice (Charles River, Wilmington, MA) were colonized with T. hyodysenteriae 94A008 by oral administration of cells harvested from TBA plates and diluted in BHI broth to approximately $2 \times 10^{7} \mathrm{cfu} / \mathrm{ml}$. Three $1-\mathrm{ml}$ challenge doses were administered at 0,18 and 24 hours. Mice were housed in groups of five/cage on wood chip bedding (changed twice weekly); water and pellet ration were provided ad libitum. Intestinal colonization was monitored by collecting two fecal pellets from individual mice, homogenizing in $4.5 \mathrm{ml}$ sterile BHI broth and plating duplicate samples of the homogenate in pour plates using TBA supplemented with $400 \mu \mathrm{g} / \mathrm{ml}$ spectinomycin and $25 \mu \mathrm{g} / \mathrm{ml}$ rifampicin. Plates were incubated anaerobically (see above) at $39^{\circ} \mathrm{C}$ for 72 hours; cfu were identified by hemolytic zones. A sample showing $\geq 50 \mathrm{cfu} / \mathrm{ml}$ of homogenate was considered to indicate intestinal colonization.

For drug treatment, mice successfully colonized with $T$. hyodysenteriae were dosed per os BID for four consecutive days with $0.2 \mathrm{ml}$ volumes of UK-69,753 solubilized in ethanol and diluted in sterile water to the desired concentrations; the final ethanol concentration did not exceed $5 \%$. A fresh drug solution was prepared each day and stored at $4^{\circ} \mathrm{C}$ between doses. Treatment groups consisted of five mice housed and fed as described above. A control group of four mice received $5 \%$ ethanol in water. Colonization of mice was monitored as described above.

\section{Acknowledgments}

The authors wish to thank Eugene Cisek and Shang-PoA Chang for their skillful assistance with the HPLC purification of and degredative studies on UK-69,753, MARK JEFFERSON for providing material from fermentation, PETER CORNell and JoEl ACKerman for conducting the biological studies, Dr. Justin Stroh for providing the FAB-MS data, and Dr. JOHN RUDDOCK for many helpful discussions during the course of this work.

\section{References}

1) Pacey, M. S.; M. R. Jefson, L. H. Huang, W. P. Cullen, H. Maeda, J. Tone, S. Nishiyama, K. Kaneda \& M. Ishiguro: UK-69,753, a novel member of the efrotomycin family of antibiotics. I. Taxonomy of the producing organism, fermentation and isolation. J. Antibiotics 42: 1453 1459, 1989

2) Dewey, R. S.; B. H. Arison, J. Hannah, D. H. Shih \& G. Albers-Schönberg: The structure of efrotomycin. J. Antibiotics 38: $169 \mathrm{I} \sim 1698,1985$

3) Doddrell, D. M.; D. T. PegG \& M. R. Bendall: Distortionless enhancement of NMR signals by polarization transfer. J. Magn. Reson. 48: 1490 1495, 1987

4) Aue, W. P.; E. Bartholdi \& R. R. ERnst: Two-dimensional spectroscopy: Application to nuclear magnetic resonance. J. Chem. Phys. 64: 2229 2246, 1987

5) BAX, A. \& G. Morris: An improved method for heteronuclear shift correlation by two-dimensional NMR. J. Magn. Reson. 42: $501 \sim 505,1981$

6) Berger, J.; H. H. Lehr, S. Teitel, H. Maehr \& E. Grunberg: A new antibiotic X-5108 of Streptomyces origin. I. Production, isolation and properties. J. Antibiotics 26: 15 22, 1973

7) Gullo, V. P.; S. B. Zimmerman, R. S. Dewey, O. Hensens, P. J. Cassidy, R. Orwa \& S. Omura: Factumycin, a new antibiotic (A40A): Fermentation, isolation and antibacterial spectrum. J. Antibiotics 35: 1705 1707, 1982

8) Dewey, R. S.; J. E. Flor, S. B. Zimmerman, P. J. Cassidy, S. Omura \& R. Oiwa (Merck): Discovery of A73A, a new efrotomycin-like antibiotic in fermentation broth. U.S. 4,262,002, Apr. 14, 1981

9) ZeECK, A.; H.-U. Hoppe \& I. HummeL: Die Konstitution des kirrothricins. Tetrahedron Lett. 22: 2357 2360, 1981

10) Hochlowski, J. E.; M. H. Buytendorp, D. N. Whittern, A. M. Buko, R. H. Chen \& J. B. McAlpine: Phenelfamycins, a novel complex of elfamycin-type antibiotics. II. Isolation and structure determination. J. 
Antibiotics 41: $1300 \sim 1315,1988$

11) Carter, G. T.; D. W. Phillipson, J. J. Goodman, T. S. Dunne \& D. B. Borders: LL-E19020 $\alpha$ and $\beta$, novel growth promoting agents: Isolation, characterization and structures. J. Antibiotics 41: 1511 1514, 1988

12) Frost, B. M.; M. E. Valiant, B. Weissberger \& E. L. Dulaney: Antibacterial activity of efrotomycin. J. Antibiotics 29: 1083 1091, 1976

13) Frost, B. M.; M. E. Valiant \& E. L. Dulaney: Antibacterial activity of heneicomycin. J. Antibiotics 32: 626 629, 1979

14) International Tables for X-ray Crystallography. Vol. IV. Eds., J. A. Ibers \& W. C. Hamlton, pp. 55, 99, 149, Kynoch Press, 1974

15) Sheldrick, G. M.: Desktop Shelxtl Nicolet X-Ray Instrument, 1986

16) Dirlam, J. P.; L. J. Czuba, B. W. Dominy, R. B. James, R. M. Pezzullo, J. E. Presslitz \& W. W. Windisch: Synthesis and antibacterial activity of 1-hydroxy-1-methyl-1,3-dihydrofuro\{3,4-b\}quinoxaline 4,9-dioxide and related compounds. J. Med. Chem. 22: 1118 1121, 1979 